\title{
The Influence of US Presidential Tweets on Global Markets
}

\author{
Chen Y. Wu \\ The University of Texas at Tyler \\ Vivek K. Pandey \\ The University of Texas at Tyler \\ Roger Lirely
The University of Texas at Tyler
}

Donald J. Trump is the first President of the United States to routinely use social media to comment on current events, political figures, celebrities and to make official policy announcements. We examine the effects of Trump's tweets on subjects of interest to financial markets in the U.S. and abroad. We show that general comments about the US economy have very little impact on the market. Conversely, companyspecific tweets tend to have a positive, but transient, impact. We find that Trump's tweets escalating trade disputes tend to have a lasting negative impact on the equity markets of the concerned foreign nation.

Keywords: fixed income markets, equity markets, international markets, commodity markets, social media

\section{INTRODUCTION}

Social media platforms began with GeoCities (1994), Classmates (1995) and Six Degrees (1997), but bulletin board systems (BBS), such as AOL, Compuserve and Prodigy, popular in the 1980's, can be considered predecessors to modern internet-based platforms ("Social Media," 2020). By the early 1990's, BBS began to migrate to the World Wide Web, but the emergence of modern social media platforms did not occur until the early 2000's with Friendster (2002), LinkedIn (2003), MySpace (2003), Facebook (2004) and Twitter (2006) ("Then and now," 2014).

From the earliest days of social media, individuals, businesses, politicians, celebrities, political/interest groups and pundits have used their accounts to regularly engage with like-minded users. For politicians, pundits and political/interest groups, social media platforms provide a direct means to reach voters, independent of traditional media. This is even more appealing as the reach of the social media platforms expanded at an explosive pace with each of the following having over 100 million registered users across the globe: Facebook, YouTube, Instagram, Twitter, Snapchat, Pinterest, LinkedIn, Tumblr and Telegram ("Social Media," 2020). Social media has proven to be an effective method to communicate with voters of similar political orientation and organize them as volunteers or small-scale donors. Barack Obama demonstrated this in his successful 2008 campaign. Subsequently, more politicians began to appear on Facebook, Instagram, YouTube and Twitter, with Obama becoming one of the first people to have a Twitter 
account with over 10 million followers. He announced his intention to run for re-election via a tweet, which was quickly responded to by a tweet of his eventual Republican opponent, Mitt Romney.

Trump was quick to recognize the potential of social media, and many regard him as the "first social media president" ("Donald Trump on social media," 2019). He joined Twitter in 2009, and the number of his tweets skyrocketed from less than 200 in 2010 to over 8,000 in 2013 but slackened to under 6,000 in 2014. Between June 16, 2015, when he announced his intention to become the Republican presidential candidate, and the election of November 8,2016, he posted nearly 8,000 tweets. The President-elect tweeted fewer than 400 times between November 8, 2016 and his inauguration on January 20, 2017. Since then, he has tweeted from both his personal account (@realDonaldTrump) and from the official US presidential account (@POTUS), created by Barack Obama ("Donald Trump on social media," 2019). From the earliest days of his presidency, Trump's tweets have been recognized as official statements by the US President and are scrutinized by the world at large ("Donald Trump on social media," 2019). He resumed an extraordinary pace of tweets with around 2,500 tweets in his first year in office and over 3,500 tweets in his second year in office. In 2019, the President posted 7,700 tweets to 68 million followers in (Relman, 2020).

A July 2017 poll by Fox News, widely regarded as a pro-Trump network, revealed that about $70 \%$ of voters believe his tweets hurt his agenda. A UMass-Lowell poll conducted in January 2019 showed that even the digitally-connected Americans, those between ages of 18 and 37, believe Trump tweets excessively ("Donald Trump on social media," 2019). On July 16, 2019, the House of Representatives censured him for his "racist" tweets about four Democratic Congresswomen. The censure passed with overwhelming Democratic support, but only four Republican votes. Nonetheless, Trump's support among Republican voters has held steady throughout his first three and half years in office, regardless of controversies his actions and words have generated.

\section{LITERATURE REVIEW}

The effects of Trump's tweets on financial markets have attracted little attention from academics. One exception is a working paper from 2017 which shows when Trump mentions a company by name in a tweet between November 2016 and February 2017, the price and trading volume of its stock move appreciably, as does the Bloomberg institutional investor sentiment of the company, although the impact was greater for tweets before his inauguration (Ge et al., 2017). Another study finds that Trump tweets from the first months of his presidency containing 58 keywords spanning economics, finance, public policy, politics and specific company names have no significant impact on either individual companies or market indices (Juma'h \& Alnsour, 2018).

But, industry practitioners have noticed the growing frequency of Trump tweets and their ability to move markets. Analysts at JP Morgan found certain topics of Trump's tweets such as trade, the Federal Reserve and monetary policy and those including words such as "China," "billions," and "products" do have sizeable impact on bond markets, particularly the implied interest rate volatility of 2-year and 5-year Treasuries (Newburger, 2019). Merrill Lynch analysts find that, although the US stock indices have generally done well during Trump's tenure, there is a negative relationship between the number of Trump tweets on a given day and the equity market's performance (Franck, 2019). Days with 35 (90 percentile mark for number of daily tweets) or more tweets averaged a return $-0.09 \%$ while days of 5 (10 percentile mark for number of daily tweets) or fewer tweets had an average return of $0.05 \%$ (Franck, 2019).

Other studies have found the general mood of Twitter users can be used to predict equity market returns three to four days later (Bollen et al., 2011), and the sentiment about a company expressed in Twitter is also predictive of its stock returns (Pagolu et al., 2016). Even more significant is the finding by Azar and Lo (2016) that the content of tweets referencing the Federal Open Markets Committee (FOMC) of the Federal Reserve can be used to predict future equity returns even after controlling for risk and asset-pricing factors.

Furthermore, a stock enjoying bullish investor sentiment on Twitter is rewarded with abnormal positive returns which fuels more bullish sentiment (Sprenger et al., 2014), and divergence of sentiment is correlated with greater trading volume, which confirms the power of social media to impact financial markets. A very 
recent study (Choi, 2020) reports that a one percent increase in tweets about Bitcoin results in a seven percent improvement in liquidity in the next five to ten minutes, but the effect decays after about an hour.

\section{DATA AND METHODOLOGY}

We manually tabulated Trump's tweets between Nov 8, 2016 and Aug 31, 2019 using Twitter's advanced search function. We rejected re-tweets and tweets containing similar content. This resulted in 219 tweets. We then classified them according to their potential market-moving impact: (1) Economy, or ones related to the US economy, such as unemployment, GDP growth, tax and regulatory changes, (2) Individual Companies or ones mentioning publicly-traded companies by name and (3) International Trade or ones relating to trade policies vis-à-vis China, Mexico, Canada and European Union. We further classify tweets as conveying positive or negative sentiments about the topic. Table 1 tabulates the tweets in our sample.

Daily closing prices and values for stocks, bonds, commodities and currencies are from Refinitiv's EIKON terminal and Datastream database. Bond market reaction is measured using the CBOT Long-Term US Treasury Composite Bond Futures Index. Commodity and currency market reactions are measured using returns computed from contemporaneous prices and exchange rates. Return is defined as the proportional change in value over the measured period. Hence, the return for security $i$ at time $t$ is:

$R_{i, t}=\frac{P_{i, t}-P_{i, t-1}}{P_{i, t-1}}$

Stock market reactions to tweets regarding specific companies or trade with specific countries are measured using market-adjusted abnormal returns. Company-specific abnormal returns are measured using market returns proxied by the Datastream Total Market Index for the US., whereas, country-specific equity market reactions are measured using the abnormal returns of the concerned country's Datastream Total Market Index, where the market index is proxied by the Datastream Total Market Index for the World. An abnormal return for country or company $i$ at time $t$ relative to market $m$ is:

$A R_{i, t}=R_{i, t}-R_{m, t}$

TABLE 1

NUMBER OF TRUMP'S TWEETS BY THEME. TWEETS INCLUDED IN THE STUDY ARE AT LEAST TWO DAYS APART AND WERE POSTED BETWEEN NOVEMBER 6, 2016 AND AUGUST 31, 2019

\begin{tabular}{llll}
\hline Topic & Number of Tweets & $\begin{array}{l}\text { Tweets } \\
\text { Positive Sentiment }\end{array}$ & $\begin{array}{c}\text { Conveying } \\
\text { Sweets Conveying } \\
\text { Negative Sentiment }\end{array}$ \\
\hline US Economy & 74 & 57 & 17 \\
Individual Companies & 68 & 34 & 34 \\
International Trade & 77 & 27 & 50 \\
\hline Total & 219 & 118 & 101 \\
\hline
\end{tabular}

We examine the abnormal returns on the announcement date and the cumulative effect on days following using the cumulative abnormal return:

$C A R_{i, n}=\sum_{t=1}^{n} A R_{i, t}$

Due to the fecundity of the president's tweets, we use the beta one model to compute abnormal returns. There is insufficient uneventful data to allow us to compute stable parameters for a more complicated model. To measure the statistical significance of abnormal returns, we must examine the cumulative 
abnormal returns over all events of similar nature. Hence, the cumulative average abnormal return is measured:

$$
C A R_{n}=\frac{1}{m} \sum_{i=1}^{m} C A R_{i, n}
$$

To gauge the success of a buy-and-hold trading strategy with equities, we examine buy-and-hold abnormal returns over $5,10,15,20,25$, and 30-day windows. The cumulative abnormal returns $(C A R)$ above are additive, but the buy-and-hold abnormal returns $(B H A R)$ are compounded. Hence, the BHAR for security $i$ over an $n$ day period relative to market $m$ is:

$$
B H A R_{i, n}=\left[\prod_{t=1}^{n}\left(1+R_{i, t}\right)-1\right]-\left[\prod_{t=1}^{n}\left(1+R_{m, t}\right)-1\right]
$$

We calculate the appropriate test statistics, such as the student $t$ for simple returns, the generalized sign $Z$ for CARs and the skewness corrected Tl statistic for BHARs.

We start by examining the returns to various securities on the day of and the day following the announcement. First, we study the impact of 74 of Trump's tweets regarding the US economy on the US equity index, US bond index, interest rates, prices of aluminum, steel, gold, sugar, natural gas and crude oil futures. Since Trump often engages in "tweet storms", we took care to include only qualitatively-similar tweets if they are issued at least two days apart.

We next examine the impact of Trump's 68 tweets about individual companies using the marketadjusted abnormal returns on the day of the tweet and a two-day window including the day of and the day after. Because Trump often targets media companies for criticism, we separate our sample into media and non-media companies to see if there is a meaningful difference in the stock price reaction of each subsample. We also looked at whether we can profit from implementing a buy-and-hold strategy on the stocks of companies mentioned by Trump for various windows lasting up to 30 trading days after the tweets.

Finally, we analyze the impact of 77 of Trump's pronouncements on trade-related matters by computing the world-index-adjusted abnormal returns for the country's equity index. We also examine the changes in the value of that nation's currency relative to the US dollar. We track the abnormal returns over one-day and two-day windows following the tweet, and then extend our attention to the cumulative return over a window consisting of the next thirty trading days.

\section{RESULTS}

One might expect individual stocks and commodity prices to exhibit very little reaction to Trump's tweets on the general economy of the US, because US presidents do not have much leverage on the supply and demand of the commodities we examine. Table 2 shows that is indeed what we find with a minor exception of natural gas, where Trump's tweets lead to a slight, but statistically significant, negative impact on price. Surprisingly, Table 2 shows that US equity and bond indexes are little affected by his tweets on the American economy as well, perhaps because most of such tweets are self-congratulatory, driven by previously-released economic data such as unemployment rates, number of jobs created, consumer confidence or levels of retail and home sales. 
TABLE 2

IMPACT OF ECONOMY RELATED TWEETS ON RETURNS OF STOCKS, BONDS AND COMMODITIES. TWEETS CONSIDERED ARE AT LEAST TWO DAYS APART. RET(0) IS THE SECURITY RETURN ON THE DAY OF THE TWEET AND RET $(0,+1)$ REPRESENTS THE COMPOUNDED TWO-DAY RETURN ON THE SECURITY ON THE DAY OF AND THE DAY AFTER THE TWEET

\begin{tabular}{|c|c|c|c|c|c|c|}
\hline & \multicolumn{2}{|c|}{ Overall $(n=74)$} & \multicolumn{2}{|c|}{ Positive $(n=57)$} & \multicolumn{2}{|c|}{ Negative $(n=17)$} \\
\hline & $\operatorname{Ret}(0)$ & $\operatorname{Ret}(0,+1)$ & $\operatorname{Ret}(0)$ & $\operatorname{Ret}(0,+1)$ & $\operatorname{Ret}(0)$ & $\operatorname{Ret}(0,+1)$ \\
\hline Stocks & $-0.02 \%$ & $0.06 \%$ & $0.06 \%$ & $0.11 \% * *$ & $-0.30 \%$ & $-0.07 \%$ \\
\hline Bonds & $<0.01 \%$ & $-0.05 \%$ & $<0.01 \%$ & $-0.08 \%$ & $0.03 \%$ & $0.07 \%$ \\
\hline Aluminum & $-0.04 \%$ & $<0.01 \%$ & $-0.07 \%$ & $<0.01 \%$ & $0.05 \%$ & $0.04 \%$ \\
\hline Steel & $-0.10 \%$ & $-0.17 \%$ & $-0.10 \%$ & $-0.22 \%$ & $-0.12 \%$ & $-0.02 \%$ \\
\hline Gold & $0.08 \%$ & $0.03 \%$ & $0.10 \%$ & $0.08 \%$ & $0.01 \%$ & $0.13 \%$ \\
\hline Oil & $-0.14 \%$ & $0.05 \%$ & $0.08 \%$ & $0.17 \%$ & $-0.88 \%$ & $-0.35 \%$ \\
\hline Sugar & $-0.17 \%$ & $0.02 \%$ & $-0.05 \%$ & $0.04 \%$ & $-0.54 \%$ & $-0.23 \%$ \\
\hline Natural Gas & $-0.70 \% *$ & $-0.22 \%$ & $-0.04 \%$ & $0.02 \%$ & $-1.81 \% * *$ & $-0.46 \%$ \\
\hline
\end{tabular}

$*^{*}, * * * *$ represent statistical significance at the $0.1,0.05$ and 0.01 levels respectively. Significance of returns measured using t-statistics.

Table 3 illustrates an interesting pattern in the abnormal returns of companies specifically mentioned by Trump. When the content is favorable, non-media companies experience a substantial and statisticallysignificant positive abnormal return both on the day of the tweet and the next trading day. For non-media companies, the absolute value of the impact is even larger, but the small number of such tweets (four) limited our ability to conclude whether the impact is statistically meaningful at conventional levels.

TABLE 3

MARKET ADJUSTED ABNORMAL RETURNS TO COMPANY STOCKS ON COMPANY RELATED TWEETS. AR(0) IS THE EVENT DAY ABNORMAL RETURN WHILE CAR(0, +1) IS THE TWO-DAY CUMULATIVE ABNORMAL RETURN ON THE EVENT DAY AND THE DAY AFTER

\begin{tabular}{lllllll}
\hline & \multicolumn{2}{l}{ All Companies } & \multicolumn{2}{l}{ Media Companies } & \multicolumn{2}{l}{ Non-Media Companies } \\
& $\mathrm{AR}(0)$ & $\mathrm{CAR}(0,+1)$ & $\mathrm{AR}(0)$ & $\mathrm{CAR}(0,+1)$ & $\mathrm{AR}(0)$ & $\mathrm{CAR}(0,+1)$ \\
\hline \multirow{2}{*}{ Overall } & $0.40 \% *$ & $0.84 \% * *$ & $0.81 \% * *$ & $1.27 \% * *$ & $0.17 \%$ & $0.59 \% * * *$ \\
\multirow{4}{*}{ Positive Tweets } & $(\mathrm{n}=68)$ & $(\mathrm{n}=68)$ & $(\mathrm{n}=25)$ & $(\mathrm{n}=25)$ & $(\mathrm{n}=43)$ & $(\mathrm{n}=43)$ \\
& $0.91 \% * *$ & $1.37 \% * *$ & $4.08 \% \%^{* *}$ & $4.51 \%$ & $0.49 \% * *$ & $0.95 \% * * *$ \\
\multirow{2}{*}{ Negative Tweets } & $(\mathrm{n}=34)$ & $(\mathrm{n}=34)$ & $(\mathrm{n}=4)$ & $(\mathrm{n}=4)$ & $(\mathrm{n}=30)$ & $(\mathrm{n}=30)$ \\
& $-0.10 \%$ & $0.32 \% * *$ & $0.18 \% *$ & $0.66 \% * *$ & $-0.56 \%$ & $-0.23 \%$ \\
& $(\mathrm{n}=34)$ & $(\mathrm{n}=34)$ & $(\mathrm{n}=21)$ & $(\mathrm{n}=21)$ & $(\mathrm{n}=13)$ & $(\mathrm{n}=13)$ \\
\hline
\end{tabular}

$*^{* * *},{ }^{* * *}$ represent statistical significance at the $0.1,0.05$ and 0.01 levels respectively. Significance measured via Generalized Sign Z statistics.

Table 3 also shows that for companies which are the subject of Trump's negative tweets, the market response differs depending on whether the company involved is a media company or not. Stocks of media companies unexpectedly experience a slight but positive and statistically-significant abnormal return, whereas tweets regarding non-media companies have statistically insignificant impact. 
Even then, as shown in Figure 1, the cumulative abnormal returns essentially revert to zero after 20-25 days. In short, Trump's frequent attacks on media companies are giving their stock prices a transient boost, and criticism of non-media companies are essentially ignored by investors. Figure 1 seems to suggest that, in general, media-related positive tweets appear to have a substantial impact for up to 10 days.

\section{FIGURE 1 \\ CUMULATIVE MARKET ADJUSTED ABNORMAL RETURNS FOR COMPANY STOCKS ON COMPANY RELATED TWEETS}

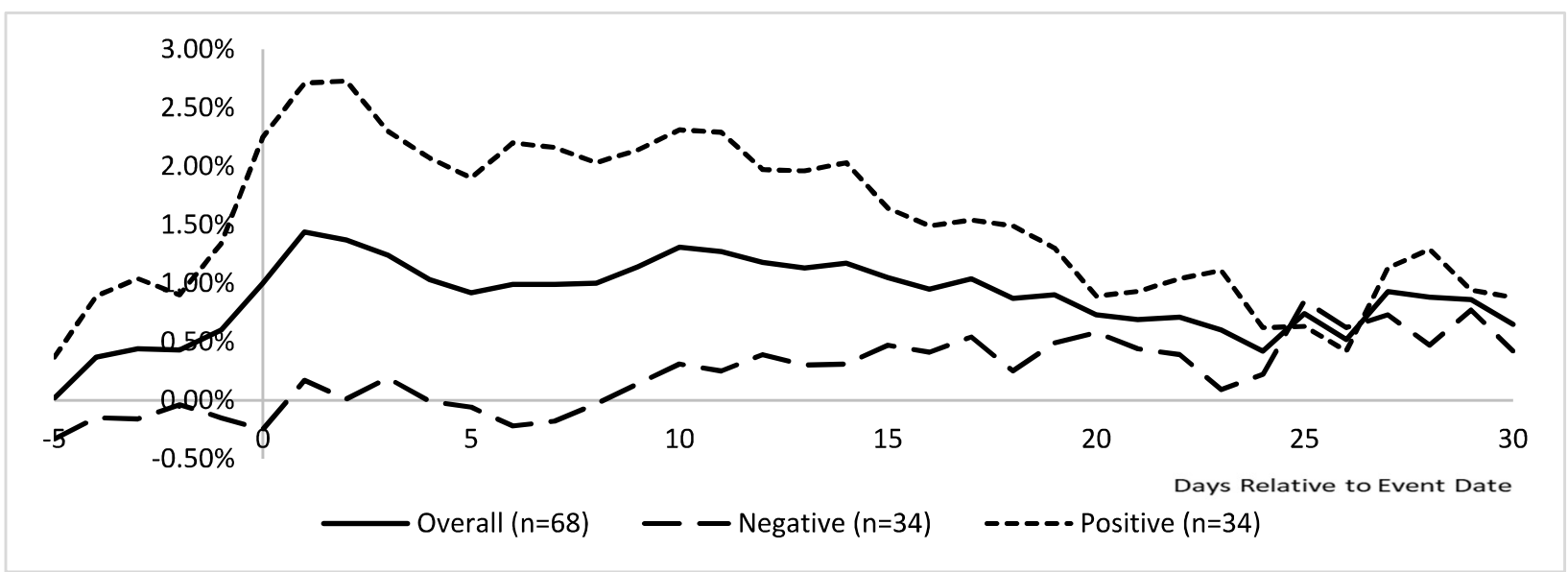

However, as shown in Table 4, buy-and-hold returns are generally not meaningfully different from 0 at traditional levels of significance. Hence, our study is unable to establish the reliability of a trading strategy for individual company stocks using these tweets.

TABLE 4
BUY AND HOLD RETURNS (BHAR) FOR MARKET ADJUSTED ABNORMAL COMPANY STOCK RETURNS OVER VARIOUS WINDOWS FOLLOWING A COMPANY RELATED TWEET

\begin{tabular}{llll}
\hline & $\begin{array}{l}\text { Overall } \\
(\mathrm{n}=68)\end{array}$ & $\begin{array}{l}\text { Positive Tweets } \\
(\mathrm{n}=34)\end{array}$ & $\begin{array}{l}\text { Negative Tweets } \\
(\mathrm{n}=34)\end{array}$ \\
\hline BHAR $(0,+5)$ & $0.29 \%$ & $0.49 \%$ & $0.10 \%$ \\
BHAR $(0,+10)$ & $0.66 \% *$ & $0.86 \%$ & $0.47 \%$ \\
BHAR $(0,+15)$ & $0.38 \%$ & $0.15 \%$ & $0.62 \%$ \\
BHAR $(0,+20)$ & $0.10 \%$ & $-0.6 \%$ & $0.79 \%$ \\
BHAR $(0,+25)$ & $-0.12 \%$ & $-0.83 \%$ & $1.06 \%$ \\
BHAR $(0,+30)$ & $-0.03 \%$ & $-0.62 \%$ & $0.57 \%$ \\
\hline
\end{tabular}

$*, * *, * * *$ represent statistical significance at the $0.1,0.05$ and 0.01 levels respectively. Significance measured via Skewness Corrected T1 Statistic

Trump is the first US president to regularly use Twitter as a method of disseminating changes in position or policy. His power as the head of the government of the nation with the largest gross domestic product at current exchange rates is clearly shown in Tables 5 and 6 . When he announces new protectionist moves or makes threats against a trading partner in 50 of his tweets, the equity index of that nation experiences a negative and statistically-significant abnormal return on the day of the tweet. Figure 2 demonstrates that over the next 20 trading days, the cumulative abnormal return continues to become more negative, and importantly, holds until the end of our 30-day window. In contrast, his announcements ameliorating trade 
tensions on 27 occasions have a statistically-significant impact only within the two-day window, including the day the tweet appeared. This impact dwindles to statistically-insignificant levels within a few days of the tweet, and the cumulative abnormal return is never meaningfully different from zero over the rest of the30-day window. In stark contrast to their ability to move equity markets downwards, Trump's tweets seem to have no influence on the value of the currencies of the nations mentioned even on a short-term basis.

Table 6 demonstrates that buy-and-hold abnormal returns remain statistically significant over each of the $5,10,15,20,25$ and 30-day windows after negative trade-related tweets. These negative returns appear to be economically meaningful as well, with a drop of 2 percent in a 15-day (or larger) window. This can provide meaningful trading opportunities, by shorting exchange-traded funds based on broad equity market indices in these respective countries. Our earlier observation that foreign exchange rates do not appear to be influenced by Trump's tweets also assures that exchange rate risk could be minimal in such trading strategies.

TABLE 5

WORLD INDEX ADJUSTED ABNORMAL RETURNS TO COUNTRY STOCK INDEXES AND THE FOREIGN NATION'S CURRENCY APPRECIATION VERSUS USD IN RESPONSE TO TRADE RELATED TWEETS. AR(0) IS THE EVENT DAY ABNORMAL RETURN WHILE CAR(0,+1) IS THE TWO-DAY CUMULATIVE ABNORMAL RETURN ON THE EVENT DAY AND THE DAY AFTER. RET(0) IS THE FOREIGN COUNTRY'S CURRENCY APPRECIATION VERSUS USD ON THE EVENT DAY AND RET $(0,+1)$ IS THE COMPOUNDED TWO-DAY CURRENCY APPRECIATION

\begin{tabular}{lllll}
\hline & \multicolumn{2}{l}{ Market Adjusted Stock Index } & \multicolumn{2}{l}{ Exchange Rate Appreciation } \\
& AR(0) & CAR $(0,+1)$ & Ret(0) & Ret $(0,+1)$ \\
\hline \multirow{2}{*}{ Overall } & $-0.14 \%$ & $-0.08 \%$ & $-0.10 \%$ & $-0.05 \%$ \\
& $(\mathrm{n}=77)$ & $(\mathrm{n}=77)$ & $(\mathrm{n}=77)$ & $(\mathrm{n}=77)$ \\
\multirow{3}{*}{ Positive Tweets } & $0.07 \% *$ & $0.30 \% * *$ & $-0.08 \%$ & $-0.01 \%$ \\
& $(\mathrm{n}=27)$ & $(\mathrm{n}=27)$ & $(\mathrm{n}=19)$ & $(\mathrm{n}=19)$ \\
\multirow{3}{*}{ Negative Tweets } & $-0.26 \% * * *$ & $-0.29 \%$ & $-0.13 \%$ & $-0.14 \%$ \\
& $(\mathrm{n}=50)$ & $(\mathrm{n}=50)$ & $(\mathrm{n}=45)$ & $(\mathrm{n}=45)$ \\
\hline
\end{tabular}

$*, * *, * *$ represent statistical significance at the $0.1,0.05$ and 0.01 levels respectively. Abnormal return significance measured via Generalized Sign Z statistics while the significance of the currency appreciation rate is measured using t-statistics.

FIGURE 2

CUMULATIVE WORLD INDEX ADJUSTED ABNORMAL RETURNS TO FOREIGN MARKET EQUITIES ON TRADE RELATED TWEETS

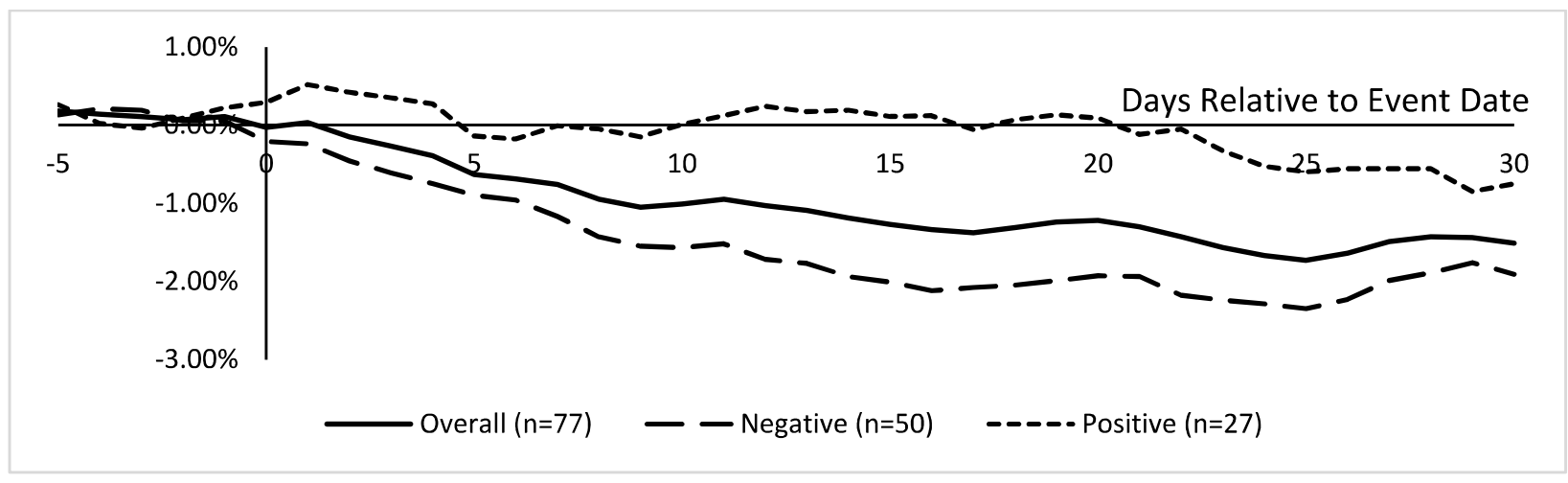


TABLE 6

BUY AND HOLD RETURNS (BHAR) FOR WORLD INDEX ADJUSTED ABNORMAL GAINS TO COUNTRY EQUITY INDICES AFTER TRADE RELATED TWEETS

\begin{tabular}{llll}
\hline & $\begin{array}{l}\text { Overall } \\
(\mathrm{n}=77)\end{array}$ & $\begin{array}{l}\text { Positive Tweets } \\
(\mathrm{n}=27)\end{array}$ & $\begin{array}{l}\text { Negative Tweets } \\
(\mathrm{n}=50)\end{array}$ \\
\hline BHAR $(0,+5)$ & $-0.73 \% * * *$ & $-0.36 \%$ & $-0.93 \% * * *$ \\
BHAR $(0,+10)$ & $-1.10 \% * * *$ & $-0.21 \%$ & $-1.58 \% * * *$ \\
BHAR $(0,+15)$ & $-1.35 \% * * *$ & $-0.11 \%$ & $-2.02 \% * * *$ \\
BHAR $(0,+20)$ & $-1.31 \% * * *$ & $-0.11 \%$ & $-2.02 \% * * *$ \\
BHAR $(0,+25)$ & $-1.85 \% * * *$ & $-0.81 \%$ & $-2.41 \% * * *$ \\
BHAR $(0,+30)$ & $-1.65 \% * * *$ & $-0.97 \% *$ & $-2.02 \% * * *$ \\
\hline
\end{tabular}

$*, * *, * * *$ represent statistical significance at the $0.1,0.05$ and 0.01 levels, respectively. Significance measured via Skewness Corrected T1 Statistics

\section{CONCLUSION}

Our analysis shows Trump's tweets about the US economy has virtually no impact on commodity prices or the US equity and bond indexes. The President singling out specific companies for favorable or unfavorable treatment has only a short-term impact on their stocks, which are almost completely dissipated over very short horizons. In contrast, Trump's tweets regarding US trade policy is extremely powerful in moving stock markets of the subject nations. Escalation of trade disputes or threats of protectionist measures have a significant negative impact on the stock indexes of the targeted nations. With the use of exchangetraded funds based on broad equity markets from these countries, it may be feasible to devise profitable trading strategies.

\section{REFERENCES}

Azar, P.D., \& Lo, A.W. (2016). The wisdom of Twitter crowds: Predicting stock market reactions to FOMC meetings via Twitter feeds. The Journal of Portfolio Management, 42(5), 123-134.

Bollen, J., Mao, H., \& Zeng, X. (2011). Twitter mood predicts the stock market. Journal of Computational Science, 2(1), 1-8.

Choi, H. (2020). Investor attention and bitcoin liquidity: Evidence from bitcoin tweets. Finance Research Letters. https://dol.org/10.1016/j.fri.2020.101555

Donald Trump on social media. (2019, October 27). In Wikipedia. Retrieved from https://en.wikipedia.org/wiki/Donald_Trump_on_social_media

Franck, T. (2019, September 3). On days when President Trump tweets a lot, the stock market falls, investment banks finds. Retrieved from https://www.cnbc.com/2019/09/03/on-days-whenpresident-trump-tweets-a-lot-the-stock-market-falls-investment-bank-finds.html

Ge, Q., Kurov, A., \& Wolfe, M.H. (2017). Stock market reactions to presidential social media usage: Evidence from company-specific tweets. Working Paper.

Juma'h, A., \& Alnsour, Y. (2018) Using social media analytics: The effect of President Trump's tweets on companies' performance. Journal of Accounting and Management Information Systems, 17(1), $100-121$.

Newburger, E. (2019, September 8). JP Morgan has created an index to track the effect of Trump's tweets on financial markets: 'Volfefe index'. CNBC. Retrieved from https://www.cnbc.com/2019/09/08/donald-trump-is-tweeting-more-and-its-impacting-the-bondmarket.html 
Pagolu, V.S., Reddy, K.N., Panda, G., \& Majhi, B. (2016, October). Sentiment analysis of Twitter data for predicting stock market movements. In 2016 international conference on signal processing, communication, power and embedded system (SCOPES) (pp. 1345-1350). IEEE.

Relman, E. (2020). Trump leaned into Twitter in 2019, tweeting twice the number of times as he did in 2018. Retrieved from https://www.businessinsider.com/trump-tweeted-twice-as-many-times-in2019-2020-1

Social Media. (2020, June 8). In Wikipedia. Retrieved from https://en.wikipedia.org/w/index.php?title=Social_media\&oldid=961371417.

Sprenger, T.O., Tumasjan, A., Sandner, P.G., \& Welpe, I.M. (2014). Tweets and trades: The information content of stock microblogs. European Financial Management, 20(5), 926-957.

Then and now: a history of social networking sites. (2014, February 4). Retrieved from https://www.cbsnews.com/pictures/then-and-now-a-history-of-social-networking-sites/ 